\title{
Social Marketing Campaign: Upaya Meningkatkan Pemahaman dan Kepatuhan Milenial Terhadap Protokol Kesehatan DKI Jakarta
}

\author{
Virgo Simamora ${ }^{1}$, Novi Theresia Kiak ${ }^{2}$, Maria Prudensiana Leda Muga ${ }^{3}$ \\ 1Fakultas Ekonomi dan Bisnis Universitas 17 Agustus 1945 Jakarta \\ ${ }^{2-3}$ Fakultas Ekonomi dan Bisnis, Unversitas Nusa Cendana, Kupang
}

\begin{abstract}
Two years after the first case was detected, Indonesia is still dealing with the spread of COVID-19. Because of a lack of individual compliance to health protocols, it is becoming increasingly difficult to control. Individual compliance is influenced by several factors, the most common of which is a lack of knowledge about health protocol. This program aims to enhance millennials' knowledge of COVID-19 and encourage them to comply with the health protocol. This program was attended by 44 millennials from RT.11/RW.6, Sunter Agung, Tanjung Priok, North Jakarta, DKI Jakarta, the province with the highest number of COVID-19 cases in Indonesia. Millennials were selected because they are more likely to have asymptomatic COVID19. This virtual training includes sharing sessions, questions and answers, and role-playing. To evaluate the difference in personal knowledge before and after the training, all participants must complete the health protocol questionnaire, previously distributed via a Google form, before and after the training. Following the training, millennial knowledge and compliance rose, according to the evaluation.
\end{abstract}

Keywords

COVID-19, health protocol, compliance

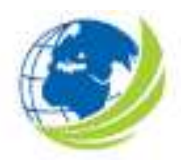

BERDAYA : Jurnal Pendidikan dan Pengabdian Kepada Masyarakat Vol 3, No.3, Desember 2021, pp. $95-102$ eISSN 2721-6381

\section{Article History}

Received 20 Sep 2021 / Accepted 25 Nov 2021 / First Published: 16 Dec 2021

To cite this article

Simamora, V., Kiak, N. T., \& Muga, M. P. L. (2021). Social Marketing Campaign: Upaya Meningkatkan Pemahaman dan Kepatuhan Milenial Terhadap Protokol Kesehatan. DKI Jakarta. BERDAYA: Jurnal Pendidikan Dan Pengabdian Kepada Masyarakat, 3(3), 95 - 102

DOI: $10.36407 /$ berdaya.v3i3.440

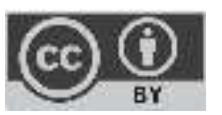

(C) The Author(s)2021

. This open access article is distributed under a Creative Commons Attribution (CC-BY) 4.0 license 


\begin{abstract}
ABSTRAK
Dua tahun setelah kasus pertama teridentifikasi, penyebaran COVID-19 masih sulit dikendalikan. Ketidakpatuhan terhadap protokol kesehatan membuat pengendalian penyebaran COVID-19 tidak mudah dilakukan. Ada beberapa faktor yang menyebabkan ketidakpatuhan. Alasan yang paling utama adalah kurangnya pengetahuan individu tentang protokol kesehatan. Kegiatan pengabdian masyarakat ini dilakukan dengan tujuan untuk meningkatkan pengetahuan dan kepatuhan milenial terhadap protokol kesehatan COVID19. Pelatihan ini diikuti oleh 44 milenial yang tinggal di RT.11/RW.6, Sunter Agung, Tanjung Priok, Jakarta Utara, DKI Jakarta yang merupakan provinsi dengan kasus COVID-19 terbanyak di Indonesia. Milenial dipilih sebagai target peserta karena kelompok ini memiliki risiko tinggi menjadi pasien COVID-19 tanpa gejala.

Pelatihan diberikan secara virtual, mulai dari sesi sharing dan dilanjutkan dengan tanya jawab serta role play. Sebelum pelatihan diberikan, seluruh peserta terlebih dahulu mengisi kuesioner tentang pengetahuan dan kepatuhan terhadap protokol kesehatan COVID-19 secara online melalui google form. Setelah pelatihan diberikan, peserta kembali mengisi kuesioner yang sama untuk kedua kalinya sehingga dapat dilihat perbandingan antara pengetahuan dan kepatuhan peserta sebelum dan setelah pelatihan diberikan. Hasil evaluasi menunjukkan bahwa tingkat pengetahuan dan kepatuhan milenial terhadap protokol kesehatan meningkat pasca pelatihan.
\end{abstract}

Kata Kunci : COVID-19, protokol kesehatan, kepatuhan
Profil Penulis

Virgo Simamora,

Fakultas Ekonomi dan Bisnis

Universitas 17 Agustus 1945 Jakarta

Novi Theresia Kiak, Maria

Prudensiana Leda Muga

Fakultas Ekonomi dan Bisnis,

Unversitas Nusa Cendana, Kupang

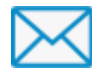

Korespondensi:

virgo.simamora@uta45jakarta.ac.id novi.kiak@staf.undana.ac.id; maria.muga@staf.undana.ac.id

Reviewing Editor

Swarmilah Hariani, Universitas Mercu Buana, Jakarta

\section{PENDAHULUAN}

Memasuki tahun kedua sejak pasien pertama COVID-19 ditemukan di Indonesia, pandemi COVID-19 masih belum berakhir. Pasca munculnya varian baru dengan pola penyebaran yang berbeda, jumlah kasus baru di Indonesia menunjukkan peningkatan yang signifikan. Pada saat kegiatan ini dilaksanakan, jumlah kasus baru di Indonesia mencapai 21095 kasus per hari Covid-19.go.id, 26 Juni 2021). Upaya pemerintah mengendalikan penyebaran COVID-19 terkendala oleh ketidakpatuhan masyarakat terhadap protokol kesehatan. Kepatuhan adalah faktor kunci keberhasilan pemerintah mengendalikan penyebaran COVID-19 (Badan Nasional Penanggulan Bencana (BNPB, 2020). Menurut Afrianti dan Rachmawati (2021), kurangnya pengetahuan individu tentang pentingnya menerapkan protokol kesehatan menjadi salah satu faktor yang menyebabkan ketidakpatuhan menerapkan protokol kesehatan. Oleh karena itu, meningkatkan pengetahuan masyarakat tentang protokol kesehatan adalah salah satu cara yang dapat dilakukan untuk 
Virgo Simamora et al.

COVID-19, health protocol, compliance

meningkatkan kepatuhan masyarakat.

Generasi Y memiliki peran penting menentukankeberhasilan pemerintah mengendalikan penyebaran COVID-19. Menurut World Health Organization (WHO), Generasi Y adalah generasi yang lahir di rentang tahun 1980 - 1995 yangberpotensi menjadi penderita COVID19 dengan kasus konfirmasi tanpa gejala (asimptomatik). Generasi Y yang terkonfirmasi asimptomatik dan tidak patuh terhadap protokol kesehatantanpa disadari dapat menjadi carrier COVID-19 terhadap orang lain. Menurut Biro Pusat Statistik (2021), jumlah Generasi Y mencapai 69.38 juta mewakili $25.87 \%$ dari total populasi Indonesia artinya kasus asimptomatik sangat tinggi di Indonesia. Oleh karena itu, kepatuhan Generasi Y terhadap protokol kesehatan berpengaruh strategis terhadap keberhasilan pemerintah mengendalikan COVID-19.

Wilayah Daerah Khusus Ibukota (DKI) Jakartaadalah wilayah dengan jumlah kasus baru tertinggi di Indonesia yaitu mencapai 9271 kasus per hari (Covid-19.go,id, 26 Juni, 2021). Sebagai pintu gerbang Indonesia, DKI Jakarta yang terintegrasi denganWilayah Dejabotabek, memiliki resiko menjadi sumber penyebaran COVID-19. Oleh karena itu, kepatuhan masyarakat DKI Jakarta khususnya Generasi Y terhadap protokol kesehatan memegang peranan penting dalam mengendalikan COVID-19 di Indonesia.

Dari uraian di atas, pelaksana memandang perlu melaksanakan kegiatan Pengabdian Kepada Masyarakat untuk memberikan pelatihan tentang protokol kesehatan COVID-19 kepada masyarakat, khususnya Generasi Y yang berpotensi menjadi kasus konfirmasi tanpa gejala (asimptomatik). Sosialisasi dan pelatihan diberikan kepada Generasi Z yang tinggal di Wilayah Daerah Khusus Ibukota (DKI) Jakarta yang sampai saat ini masih menjadi wilayah dengan jumlah pasien tertinggi di Indonesia.

\section{Sasaran Kegiatan:}

Sasaran kegiatan ini adalah Generasi Y yang berusia 30 - 40 tahun pada tahun 2020 dan beresiko menjadi pasien tanpa gejala (asimptomatik) serta berpotensi menjadi carrier COVID-19 tanpa disadari. Melalui kegiatan PKM ini, pengetahuan dan kepatuhan Generasi terhadap protokol kesehatan dapat ditingkatkan sehingga Generasi Y dapat mendukung upaya pemerintah mengendalikan penyebaran COVID-19.

\section{Materi}

\section{MATERI DAN METODE}

Istilah social marketing pertama sekali diperkenalkan oleh Kotler dan Zaltman (1971) melalui artikelnya yang berjudul "An Approach to Planned Social Change". Menurut Kotler \& Zaltman (1971) social marketing adalah "a promising framework for planning and implementing social change". Tujuan social marketing adalah mendorong terjadinya perubahan sosial di dalam masyarakat melalui perubahan perilaku individu (Hastings \& McDermont, 2006). 
Dengan menggunakan prinsip bauran pemasaran yang diadopsi dari marketing komersial, social marketer mempromosikan perilaku yang disarankan (suggested behaviour) dan manfaat sosial (social benefit) yang akan diperoleh individu yang patuh mengadopsi perilaku baru tersebut. Promosi dilakukan melalui kampanye sosial dengan menggunakan media komunikasi yang dapat menjangkau kelompok tertentu atau kelompok masyarakat yang lebih luas. Di dalam literaturesocial marketing, perilaku yang direncanakan disebut sebagai positive social behavior (Prochaska, 1994) suggested behavior (Kotler \& Zaltman, 1971), desired behaviour(Hastings \& McDermont, 2006),healthier behaviour (MacFadyen et al., 1999).

Merujuk pada pemahaman teoritis tentang social marketing di atas, cara terbaik untuk mengendalikan penyebaran COVID-19 adalah dengan meningkatkan tingkat pemahaman individu terhadap protokol kesehatan melalui kegiatansocial marketing campaign (SMC) Kegiatan dilakukan dengan melibatkan pemerintah, organisasi swasta dan kelompok masyarakat untuk lingkungan di sekitarnya. SMC difokuskan pada kampanye benefit yang diperoleh oleh individu yang patuh terhadap protokol kesehatan. Materi tentang benefit mencakup materi tentang hidup sehat dan terhindar dari penularan COVID-19 yang beresiko tinggi terhadap kematian.

Pemahaman yang baik tentang benefit, mendorong individu mengadopsi perilaku sesuai protokol kesehatan yaitu selalu menggunakan masker, menjaga jarak dan mencuci tangan ketika berada di dalam suatu kerumunan. Perubahan perilaku dalam skala besar akan berdampak pada munculnya perubahan social yang mengarah pada hidup yang lebih berkualitas.

\section{Lokasi dan Peserta}

Kegiatan dilaksanakan di RT.11/RW.6, Sunter Agung, Tj. Priok, Kota Jakarta Utara, Daerah Khusus Ibukota Jakarta. Target kegiatan adalah Generasi Y yang disebut kelompok milenial yang berusia30 40 tahun di tahun 2020 .

\section{Prosedur dan Metode}

Prosedur kegiatan ini diawali dengan temuan fakta bahwa tingkat kepatuhan masyarakat terhadap protokol kesehatan. Hasil penelitian Simanjuntak (2020) menemukan bahwa tingkat kepatuhan masyarakat di tempat ibadah baru mencapai $68.96 \%$; pelayanan pubik $83.85 \%$, di pasar tradisiona $59.6 \%$, di mall 80.71\%, di tempat kerja 86\%. Disamping itu, (Simanjuntak, 2020) menemukan bahwa usia > 60 tahun lebih patuh terhadap protokol kesehatan dibandingkan usia muda. Berdasarkan fenomena tersebut, pelaksana bersama mahasiswa Universitas 17 Agustus 1945 (UTA'45) Jakarta tertarik untuk melakukan kegiatan pengabdian masyarakat dengan mengangkat tema Social Marketing Campaign : Upaya Meningkatkan Pemahaman dan Kepatuhan Milenial Terhadap Protokol Kesehatan.

\section{Pelaksanaan Kegiatan}

\section{HASIL DAN PEMBAHASAN}

Kegiatan pengabdian masyarakat ini dilaksanakan dalam 3 tahapan sebagai berikut:

\section{Tahap Persiapan}

Pada tahap ini, pelaksana menyusun kuesioner yang berisi pertanyaan tentang protokol kesehatan, manfaat positif yang diperoleh oleh individu yang patuh dan ancaman yang dihadapi oleh individu yang tidak patuh menerapkan protokol kesehatan. Pada tahap ini, pelaksana juga membuat daftar 
peserta yang menjadi target sasaran yaitu kelompok milenial yang tinggal di Sunter Podomoro, Jakarta Utara.

\section{Tahap Pelaksanaan}

Kegiatan diawali dengan pengisian kuesioner oleh target audience melalui google form. Pengisian kuesioner sudah dapat dilakukan sejak tanggal 14 Desember 2020 dengan memberikan akses pengisian kuesioner kepada seluruh peserta. Terdapat 44 milenial yang berpartisipasi dan melakukan pengisian kuesioner. Ke 44 milenial tersebut kemudian diundang untuk mengikuti sesi pelatihan, tanya jawab dan role play yang dilaksanakan tanggal 21 Desember 2020 secara virtual. Metode pelatihan diberikan melalui sharing session, tanya jawab dan role play perilaku menggunakan masker, menjaga jarak dan mencuci tangan sesuai standar World Health Organization (WHO). Sharing session dipandu oleh Virgo Simamora dari Universitas 17 Agustus 1945 Jakarta yang menyampaikan materi tentang perilaku yang disarankan (desired behaviour) yaitu perilaku sesuai protokol kesehatan dan manfaat (beneficial value) dari kepatuhan terhadap protokol kesehatan yaitu terhindar dari penularan Covid-19.

Sesi sharing session berlangsung selama 15 menit secara virtual. Sesi tanya jawab dipandu Novi Theresia Kiak dari Universitas Nusa Cendana, Kupang. Pertanyaan yang diajukan peserta jenis jenis masker yang memproteksi pengguna secara optimal dari penuluaran Covid-19, waktu yang tepat mengganti masker dan tips memilih hand sanitizer yang tepat. Sesi role play dipandu oleh Maria Prudensiana Leda Muga dari Universitas Nusa Cendana Kupang yang menunjukkan tentang praktek penerapan social distancing yang benar dan praktek cuci tangan sesuai standar WHO.

Setelah sharing session, tanya jawab dan role play, peserta diminta mengisi kembali kuesioner yang sama pasca pelatihan.



Gambar 1. Pelaksanaan kegiatan

Sumber: dokumentasi tim di lapangan 


\section{Tahap Evaluasi}

Setelah kegiatan selesai, dilakukan evaluasi berdasarkan data yang telah dikumpulkan melalui kuesioner. Dari hasil pengolahan data diperoleh tingkat pemahaman dan tingkat kepatuhan sebelum dan sesudah pelatihan dan perbedaan tingkat pengetahuan sebelum dan sesudah training dengan menggunakan uji t. Hasil pengujian menunjukkan bahwa diperoleh probability .000 $<0,05$ artinya $\mathrm{H} 0$ ditolak dan ada perbedaan tingkat pengetahuan sebelum dan sesudah pelatihan diberikan.

\section{KESIMPULAN}

Pelaksanaan kegiatan PKM telah berjalan lancar dan hasil evaluasi menunjukkan bahwa ada manfaat yang diperoleh peserta yang termasuk usia kelompok milenial yang tinggal di di RT.11/RW.6, Sunter Agung, Tj. Priok, Kota Jakarta Utara, Daerah Khusus Ibukota Jakarta.

Dengan meningkatnya tingkat pengetahuan dan kepatuhan milenial terhadap protokol kesehatan, milenial yang berpotensi menjadi penderita tanpa gejala, dapat berkontribusi menekan laju penyebaran COVID-19.

\section{Saran Kegiatan lanjutan}

Untuk mempertahankan tingkat kepatuhan milenial terhadap protokol kesehatan, secara berkala perlu diberikan social marketing campaign dengan melalui pelatihan untuk mempertahankan kepatuhan milenial terhadap protokol kesehatan.

\section{REFERENSI}

Afrianti Novi, Rahmiati Cut (2021). Faktor-faktor yang mempengaruhi kepatuhan masyarakat terhadap protokol kesehatan covid-19. 001, 113-124.

Hastings, G., \& McDermont, L. (2006). Putting Social Marketing into Practice.

Kotler, P., \& Zaltman, G. (1971). Social marketing: An approach to planned social change. Social Marketing Quarterly, 5(3-4), 7-20. https:/ / doi.org/10.1080/15245004.1996.9960973

MacFadyen, L., Stead, M., \& Hastings, G. (1999). A Synopsis of Social Marketing. 1(2), 12-17.

Proska, J. \& Tucek, S. (1994) Mechanisme of steric and cooperative actions of alcuronium on cardiac muscarinic acetylchonline receptors 45(4), 709-717

Simanjuntak, E. (2020). Diet composition and trophic niche similarities of engraulid fishes in Diet composition and trophic niche similarities of engraulid fishes in Pabean bay, Indramayu, Indonesia. https://doi.org/10.1088/1755-1315/404/1/012056

Sinuraya, S. I., Darwin, M., Keban, Y. T., \& Sukamdi, S. (2018). Diperlukan Pendekatan Kebijakan Adaptif Untuk Penguatan Modal Umkm Di Kabupaten Sleman. Jurnal Kawistara, 8(2), 137. https://doi.org/10.22146/kawistara.33344 
About Authors

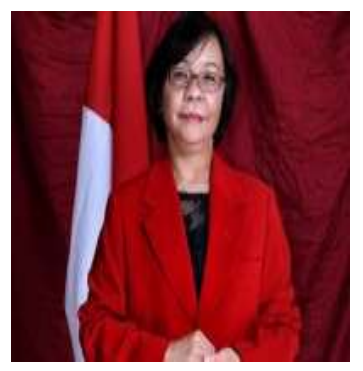

Dr. Virgo Simamora, M.B.A adalah Dosen Tetap pada Fakultas Ekonomi dan Bisnis Universitas 17 Agustus 1945 Jakarta. Penulis merupakan dosen pengampu Mata Kuliah Manajemen Strategi, Business Plan, Manajemen Pemasaran dan Metode Penelitian. Penulis dapat dihubungi di alamat email: virgo.simamora@uta45jakarta.ac.id

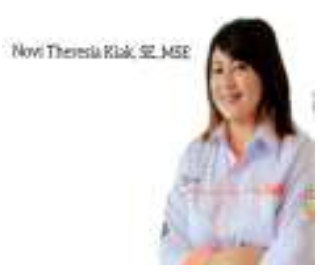

Novi Theresia Kiak, SE., M.SE. adalah dosen tetap Program studi Ekonomi Pembangunan, Fakultas Ekonomi dan Bisnis, Universitas Nusa Cendana. Penulis merupakan dosen pengampu mata kuliah ekonomi publik, dan keuangan daerah, dan makro ekonomi. Penulis dapat dihubungi di alamat email : novi.kiak@staf.undana.ac.id



Maria Prudensiana Leda Muga, SE., M.Si., Akt adalah dosen tetap Program Studi Akuntansi, Fakultas Ekonomi dan Bisnis, Universitas Nusa Cendana. Penulis merupakan dosen pengampu mata kuliah Akuntansi Keuangan Menengah I dan II, Akuntansi Keuangan Lanjutan I dan II dan Analisa Laporan Keuangan. Email: maria.muga@staf.undana.ac.id

\section{Declarations}

\section{Funding}

Kegiatan ini merupakan bagian dari program Pengabdian Kepada Masyarakat yang didanai oleh Fakultas Ekonomi dan Bisnis, Universitas 17 Agustus 1945 Jakarta.

\section{Competing Interests}

Tidak ada konflik kepentingan untuk diungkapkan. 